\title{
TWO NEW SPECIES OF POGONOPHORA FROM THE NORTH-EAST ATLANTIC
}

\author{
By Eve C. Southward \\ From the Plymouth Laboratory
}

(Text-figs. I-2)

In May 1958 it was thought that all species of Pogonophora so far discovered in the north-east Atlantic belonged to the genus Siboglinum Caullery (Southward \& Southward, I958). Since then I have had the opportunity of examining further collections from deep water off the British Isles and Spain. At least two species of multitentaculate pogonophores have been discovered, and reexamination of some material collected in May 1958 shows that one of the species was also present in these collections. Although considerable material belonging to other species remains to be worked up it has been thought worth while to describe these two species first. One is widespread and can be locally abundant, while the other is the largest pogonophore so far found in the Atlantic. Both are the first Atlantic representatives of their respective genera.

All my material was collected during cruises of R.V. 'Sarsia'. I am grateful to Captain C. A. Hoodless and the crew of 'Sarsia' for their continued interest in deep-sea dredging. I am also indebted to my husband and to Dr J. B. Gilpin-Brown who picked out the specimens, and to Dr J. S. Alexandrowicz who very kindly assisted me with the translation of Russian and German.

\section{Oligobrachia ivanovi sp.nov.}

Only one specimen of this species has been found. Its tube is black and completely opaque, and was $25 \mathrm{~cm}$ long before being broken to remove the animal. The diameter of the tube varies along its length from 0.5 to $0.9 \mathrm{~mm}$. The wall is stiff and is made of several layers of brown material with a transparent lining layer; its outer surface has narrow raised rings at fairly regular intervals (Fig. I, A). The animal is $95 \mathrm{~mm}$ long, and since only Io $\mathrm{mm}$ of the post-annular region of the trunk is present the complete animal must have been considerably longer. Its diameter is about $0.5 \mathrm{~mm}$ and its colour is greenish brown with brown tentacles and red blood. There are seven tentacles, coiled together, which are $12 \mathrm{~mm}$ long. Each has a double row of pinnules along the inner side (the length of the pinnules being about equal to the diameter of the tentacle) and a band of brown spots on the outer side (Fig. I, D). The tentacles are joined to the protosoma in a circle just in front of a slight 
transverse groove (Fig. I, B). The protosoma is about $0.8 \mathrm{~mm}$ long and is separated from the mesosoma by an oblique groove which reaches the anterior point of the bridle on the dorsal side. Patches of white glands are present on the proto- and mesosoma and their positions are shown in Fig. I, B and C, by heavy stipple. The anterior part of the metasoma or trunk, called the metameric region in other genera, has white epidermal glands arranged in two

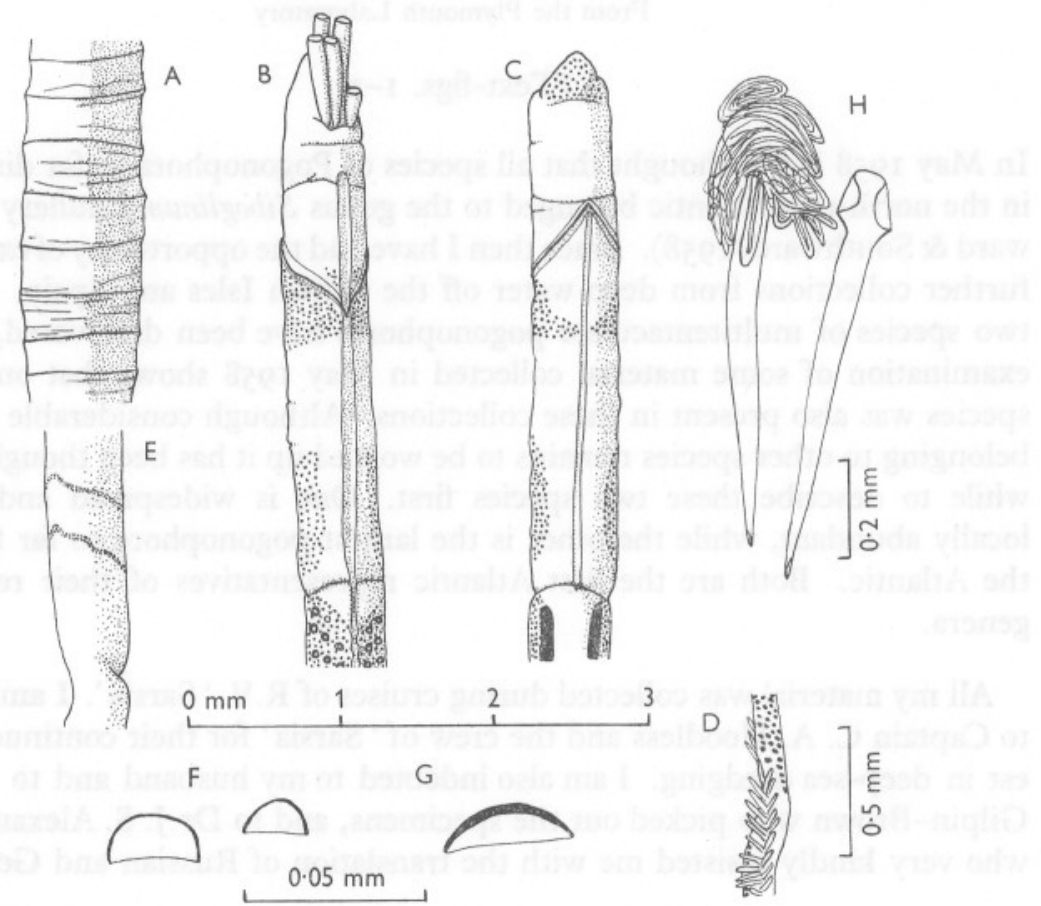

Fig. I. Oligobrachia ivanovi: A, part of tube (surface view); B, anterior end, ventral view; C, anterior end, dorsal view; D, part of tentacle; E, girdle region; F, G, adhesive plates from smaller and larger papillae of trunk; $\mathrm{H}$, spermatophores, filament removed from one.

lateral bands separated by a deep groove ventrally and by two dark brown stripes dorsally. Between the brown stripes lies the dorsal ciliated band which is pinkish white. The white bands are spotted with 3 to 4 rows of clear patches which mark the openings of internal glands. These patches lie in regular oblique lines and show up clearly because they are surrounded by brown rings. This glandular region of the body is ro $\mathrm{mm}$ long. The second region of the metasoma lacks epidermal glands but bears numerous small papillae arranged in two irregular rows along the ventral side for about $50 \mathrm{~mm}$. The rows of small papillae are followed by large papillae, arranged in 3 to 4 rows, extending for $10 \mathrm{~mm}$, while the last $5 \mathrm{~mm}$ of the pre-annular region is devoid of all but a few small papillae. Both large and small papillae are armed with 
half-moon-shaped adhesive plates (Fig. I, G), but the plates are difficult to see because they are almost colourless. There are two girdles (annuli), which both encircle the body completely, and each is made up of 2 to 3 rows of platelets. The last $10 \mathrm{~mm}$ of the body has no papillae, adhesive plates or epidermal glands and is broken off abruptly. The pre-annular part of the trunk contains spermatophores which are $0.85 \mathrm{~mm}$ long and spindle-shaped. When the filament is removed the filamentar end of the spermatophore is seen to be flattened and drawn out into two flaps, which are usually folded inwards (Fig. I, H).

The specimen on which this description is based was collected on 28 November 1958 at $48^{\circ} 26^{\prime} \mathrm{N}$., $10^{\circ} 8^{\prime} \mathrm{W}$.; depth $730-780 \mathrm{fm}$.

This new species has been named after Prof. A. V. Ivanov of Leningrad, who has already described 17 species of Pogonophora from the Pacific and Arctic Oceans, including the only other species of Oligobrachia.

$O$. ivanovi differs from $O$. dogieli Ivanov (1957) in having adhesive plates on the trunk papillae, and in this respect it resembles Birsteinia vitjasi Ivanov (I952) and confirms Ivanov's thesis that the two genera are closely related. The spermatophores of Oligobrachia dogieli and $O$. ivanovi both have winglike flaps at the filamentar end while there are no such flaps in Birsteinia or any other pogonophore yet described. Other characters in common between the two species of Oligobrachia are the curious patches or spots on the tentacles, and the comparatively long pinnules. The tentacles in Birsteinia have very short pinnules and, apparently, no spots or glands of any sort (Ivanov, 1952).

\section{Polybrachia capillaris sp.nov.}

The tubes are dark chestnut brown and look very much like hairs; the specific name capillaris refers to this likeness. The tube wall is stiff and, in the anterior part at least, is made up of short overlapping segments (Fig. 2, A). Occasionally the colourless lining layer extends a few $\mathrm{mm}$ beyond the first segment. The first few segments are pale brown and unringed; the later segments and the unsegmented part of the tube are marked with regular light and dark brown rings (Fig. 2, A), or half rings. The posterior end of the tube is yellow; the wall is thinner, but still ringed, and is occasionally surrounded by short segments of a darker outer layer. The diameter is constant along any individual tube and may be from 0.12 to $0.17 \mathrm{~mm}$ in different individuals, but is usually between 0.13 and $0.14 \mathrm{~mm}$.

It is difficult to assess the length of the complete tube or animal, since all the specimens seem to be broken, but the longest fragment of tube is $12 \mathrm{~cm}$ long. The animal itself may possibly reach $55 \mathrm{~mm}$. A specimen (from the Spanish material) that seems to be nearly complete has been chosen as the type and its measurements are given below, followed by the range, in parentheses, found in other specimens: diameter $0.12 \mathrm{~mm}(0.10-0.12)$; total length $30.6 \mathrm{~mm}$; 
length of pre-annular part $10 \mathrm{~mm}(5-15)$; length of post-annular part $20 \cdot 6$ $\mathrm{mm}$ (up to 39 ); length of proto- and mesosoma together $0.75 \mathrm{~mm}(0.5-1 \cdot 0)$; length of coiled tentacles $\mathrm{I} \cdot 5 \mathrm{~mm}(0 \cdot 5-2 \cdot 2)$.

The pre-annular part of the body grows longer as the gonads and gametes begin to develop. It is less than $7 \mathrm{~mm}$ long in immature specimens; 7-10 $\mathrm{mm}$ long in females and 10-15 mm long in males.

There are from two to four tentacles but two is the most common number (II specimens have 2, 3 specimens have 3,2 specimens have 4 ) and the type

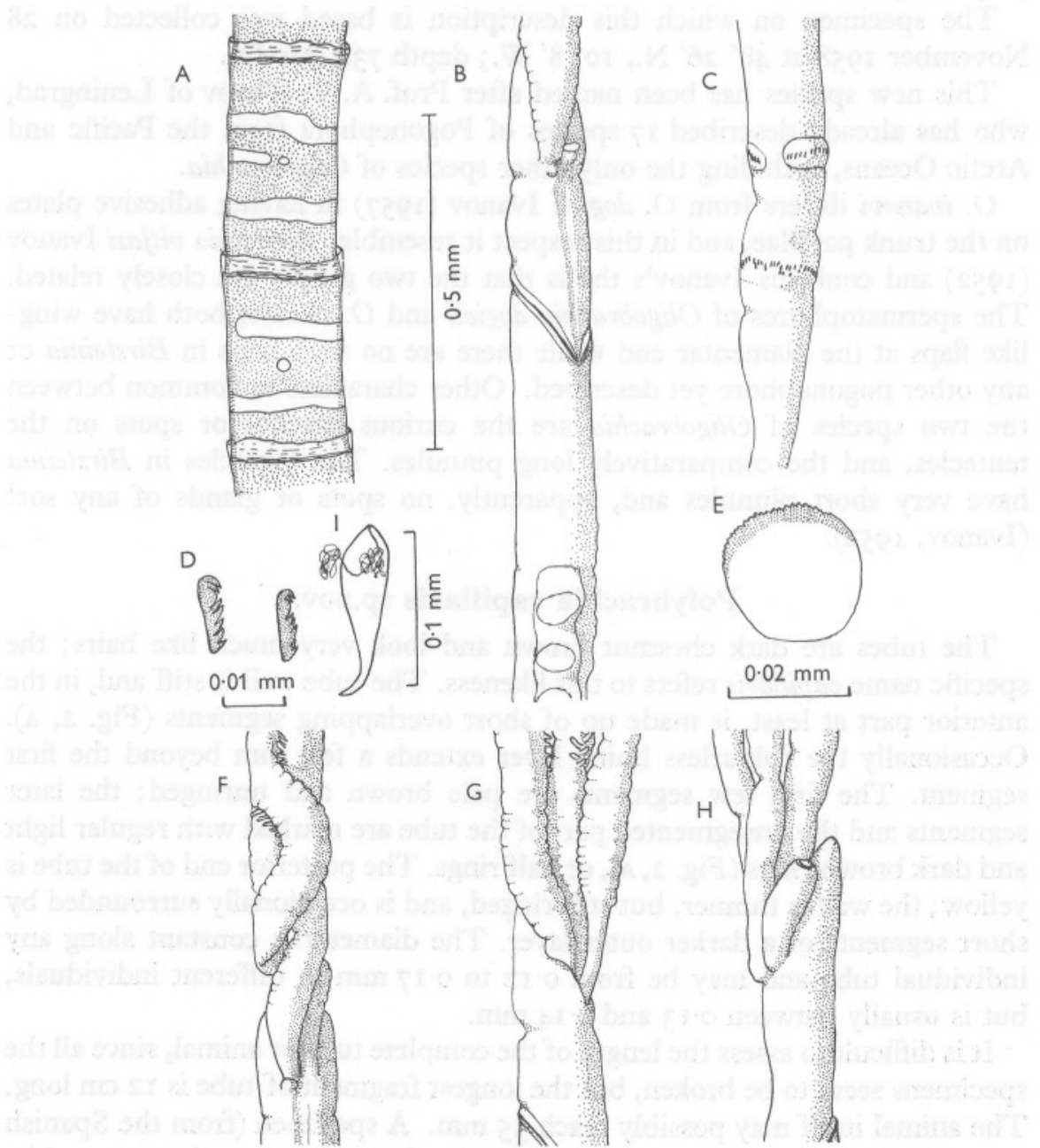

Fig. 2. Polybrachia capillaris: A, part of tube; B, anterior end of type specimen, ventral view; C, girdle region; D, girdle platelets (uncini), side view; E, adhesive plate; F, G, H, anterior ends of specimens with 2, 3 and 4 tentacles; I, spermatophore. 
specimen has two; they are coiled together into a tight spiral inside the tube and each one has a double row of pinnules (Fig. 2, F, G). Specimens with two tentacles often have a small swelling behind the base of one of them, which may be the first sign of the development of a third. The protosoma is very short (about one-quarter to one-fifth the length of the mesosoma) and is separated from the mesosoma by a shallow groove on the ventral side only (Fig. 2, B). The bridle lies on a broad ridge and is not complete on the dorsal side, but on the ventral side the two halves are sometimes separate (Fig. 2, B) and sometimes joined. There is a wide groove along the ventral side between the base of the tentacles and the bridle.

The septum between the mesosoma and metasoma can be seen through the body wall, but there is no external groove. The metameric region is short and has only 6-13 pairs of glandular papillae ( 7 in the type specimen). The first 4 or 5 of these papillae are devoid of adhesive plates, but all the other papillae on the metasoma bear small round plates (Fig. 2, E). Behind the paired papillae is a long region bearing occasional isolated papillae and ending in a close row of up to 15 large papillae just before the girdles. The two girdles are made up of single or semi-double rows of small toothed platelets (Fig. 2, C, D). The post-annular region bears transverse rows of two or three papillae at intervals of about $\mathrm{I} \mathrm{mm}$.

Mature males contain flat, leaf-like spermatophores, with very fine filaments (Fig. 2, I).

Three species of Polybrachia are already known. They are: P. gorbunovi (Ivanov, I949), P. annulata Ivanov (1952) and P. barbata Ivanov (I952). $P$. capillaris has the following characters in common with other species of Polybrachia: part of the tube is built up of short overlapping segments; the tentacles bear pinnules; both paired and unpaired trunk papillae bear adhesive plates; the post-annular papillae are arranged in transverse rows, and the spermatophores are of similar shape to those so far described for Polybrachia. There are some differences which suggest that the new species might belong to a separate, new, genus: the number of tentacles is small compared with $18-73$ in other species; there are no circular grooves on the proto- and mesosoma, apart from the incomplete one separating the two segments; the new species is only about half the size of the smallest species previously known. For the present it seems best not to propose a new generic name for a species obviously closely related to Polybrachia.

$P$. capillaris has been collected at six stations, which are listed below:

\begin{tabular}{|c|c|c|c|}
\hline Date & Position & $\begin{array}{c}\text { Depth } \\
\text { (fm.) }\end{array}$ & No. of specimens \\
\hline I6. v. 58 & $47^{\circ} 56^{\prime}$ N., $\quad 7^{\circ} 57^{\prime} \mathrm{W}$ & $340-350$ & I empty tube \\
\hline 16. v. 58 & $47^{\circ} 50^{\prime}$ N., $7^{\circ} 57^{\prime} \mathrm{W}$ & $300-450$ & 3 (and I empty) \\
\hline 6. viii. $5^{8}$ & $43^{\circ} 43^{\prime}$ N., $\quad 4^{\circ} 02^{\prime} \mathrm{W}$ & $680-970$ & I 2 (and many empty) \\
\hline 28. xi. 58 & $48^{\circ} 26^{\prime}$ N., $10^{\circ} 08^{\prime} \mathrm{W}$ & $730-780$ & 2 (and 2 empty) \\
\hline 30. xi. 58 & $48^{\circ} 39^{\prime}$ N., $\quad 9^{\circ} 50^{\prime} \mathrm{W}$ & $750-850$ & 2 \\
\hline 3o. xi. 58 & $48^{\circ} 40^{\prime} \mathrm{N} ., \quad 9^{\circ} 48^{\prime} \mathrm{W}$ & $600-680$ & I \\
\hline
\end{tabular}


Some of these specimens were previously recorded as empty tubes of Siboglinum inerme ${ }^{1}$ (Southward \& Southward, 1958), but the description of $S$. inerme was based entirely on genuine specimens.

Type specimens of Oligobrachia ivanovi and Polybrachia capillaris have been sent to the British Museum (Natural History).

\section{SUMMARY}

Two new species of Pogonophora are described. Oligobrachia ivanovi is recorded from a depth of $730-780 \mathrm{fm}$. off the mouth of the English Channel; Polybrachia capillaris is recorded from depths of $340-970 \mathrm{fm}$. at various stations off the mouth of the English Channel and one station off the north coast of Spain.

\section{REFERENCES}

Ivanov, A. V., 1949. A new representative of the class Pogonophora. Zool. Zh. SSSR, Vol. 28, pp. 78-84. (Russian.)

- 1952. New Pogonophora from far eastern seas. Zool. Zh. SSSR, Vol. 31, pp. 372-91. (Russian.)

— I957. Neue Pogonophora aus dem nordwestlichen Teil des Stillen Ozeans. Zool. Fb., Abt. I, Bd. 85, pp. 430-500.

Southward, E. C. \& Southward, A. J., 1958. On some Pogonophora from the north-east Atlantic, including two new species. F. mar. biol. Ass. U.K., Vol. 37, $627-32$.

1 The name $S$. inermis was used in the original description, it should of course be $S$. inerme. 